\title{
PEMIKIRAN TASAWUF ORTODOKS DI ASIA TENGGARA (TELAAH ATAS KONTRIBUSI AL-RANIRÎ, AL-SINGKILÎ, DAN AL-MAKASARI)
}

\author{
Ali Masrur \\ UIN Sunan Gunung Djati Bandung \\ Kontak: Komplek Citra Panyileukan AB II/No. 6 Cipadung-Bandung, Hp. 087822999438
}

\begin{abstract}
Sufisme, sebagai salah satu bagian dari khazanah Islam, dapat dikelompokkan kedalam dua varian. Pertama, sufisme yang bercorak ortodoks dan sufisme yang bercorak heterodoks. Jika yang pertama, lebih menekankan pada sikap moderat dan mengupayakan adanya keselarasan antara pengalaman mistik dengan aturan-aturan syariat, maka yang kedua, lebih menitikberatkan pada pengalaman fana daripada ajaran syariat. Dua model pemikiran sufisme ini, sangat mempengaruhi pemikiran dan gerakan sufisme di Nusantara pada abad ke-16 dan ke-17. Sufisme heterodoks mewujudkan dirinya dalam pandangan-pandangan Hamzah Fansuri (w. sebelum 1607) dan Syamsuddîn al-Sumatranî (w. 1630), sementara sufisme ortodoks terdapat dalam pikiran-pikiran Nuruddîn al-Ranirî (w. 1658), Abdurrauf alSingkilî (1615-1693), dan Syeikh Yusûf al-Makasarî(1627-1699). Karena dua aliran ini berangkat dari pemahaman dan metode yang berbeda, pengaruhnya pada gerakan sufisme Nusantara telah memuncul-kan persoalan baru dan konflik yang tak berkesudahan. Seperti terlihat pada tulisan di bawah ini, penulis hanya menelisik tentang corak sufisme ortodoks dengan mengupas pemikiran tokoh-tokoh sufi nusantara, yaitu al-Ranirî, al-Singkilî, dan alMakasarî.
\end{abstract}

\section{KEY WORDS}

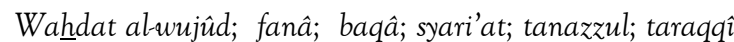

DOI: https://doi.org/10.15575/saq.v1i2.1431

\section{A. PENDAHULUAN}

Dalam khazanah pemikiran sufisme Islam, telah dikenal dua aliran besar sufisme: aliran ortodoks dan heterodoks. Sufisme ortodoks yang disebut juga dengan sufisme amali adalah aliran pemikiran sufi yang pendapatpendapatnya bersifat moderat dan selalu ingin menyelaraskan pengalaman-pengalaman mistik, di satu sisi, dengan aturan-aturan syariat, di sisi lain. Pengalaman mistik mereka selalu dirujukkan kepada al-Qur`an dan sunah agar tidak melewati batas-batas yang wajar. Pendek-nya, syariat menjadi ukuran untuk menilai apakah sebuah pengalaman itu dianggap absah atau tidak sebagai sebuah pengalaman spiritual. Jika pengalaman spiritual

\footnotetext{
${ }^{1}$ Abu al-Wafa' al-Ghanimi al-Taftazani, Sufi dari Zaman ke Zaman, terj. Ahmad Rofi' Utsmani, Pustaka, Bandung, 1985, hal. 95.
}

itu selaras dengan syariat maka dipandang absah dan jika bertentangan, tentu dianggap menyimpang.

Di sisi lain, sufisme heterodoks atau sufisme filosofis adalah aliran para sufi yang lebih mementingkan pengalaman fanâ daripada ajaran syariat yang seringkali memunculkan syathahât atau kata-kata janggal dan kontroversial. Hal ini selanjutnya membawa mereka kepada konsep penyatuan antara manusia dan Tuhan seperti yang terjadi dalam konsep wahdatul wujûd dan hulûl. ${ }^{1}$ Tokohtokoh seperti al-Ghazâlî dan al-Qusyairî dapat dimasukkan ke dalam aliran pertama sementara al-Hallâj dan Ibn Arabî termasuk aliran kedua. 
Dua aliran pemikiran sufisme ini, sejak awal perkembangan Islam, seringkali berbeda pendapat dan tidak jarang perbedaan pendapat di kalangan mereka itu pada gilirannya menimbulkan konflik yang sangat serius. Konflik itu memuncak pada suatu peristiwa yang tidak akan dilupakan oleh umat Islam sampai kapanpun, yaitu dijatuhkannya hukuman mati atas persetujuan para ahli hukum di Bagdad kepada seorang wakil sufisme heterodoks pada abad ke-3 H/ 9 M, al-Husein bin Mansur al-Hallâj, yang pernah menjadi murid Junaid al-Bagdâdî tetapi kemudian diusir oleh gurunya karena tuduhan menyamakan dirinya dengan Tuhan dalam ucapannya "anâ al-Haqq” (Aku adalah Yang Maha Benar) dan tuduhan menipu orang banyak dengan sihir. Ia didera di depan publik, dilumpuhkan anggota badannya, digantung, dipancung dan dibakar. ${ }^{2}$

Dua model pemikiran sufisme itu, yakni ortodoks (amali) dan hetero-doks (falsafi) pada perkembangannya juga mempengaruhi pemikiran dan gerakan sufisme di Nusantara pada abad ke-16 dan ke-17. Sufisme heterodoks mewujudkan dirinya dalam pandanganpandangan Hamzah Fansuri (w. sebelum 1607) dan Syamsuddin as-Sumatrani (w. 1630) mengenai paham wujudiyah sementara sufisme ortodoks terdapat dalam pikiran-pikiran Nuruddin al-Ranirî (w. 1658), Abdurrauf alSingkilî (1615-1693), dan Syeikh Yusuf alMakasari (1627-1699). Maka tidak heran, bila dalam perkembangannya juga muncul ketegangan dan konflik yang berkepanjangan antara dua penganut ajaran tersebut sebagaimana terjadi pada para pendahulu mereka. ${ }^{3}$ Dalam kaitan itulah, tulisan berikut ini menjelaskan berbagai sumbangan dan upaya yang telah dilakukan oleh para sufi ortodoks tersebut dalam memperbaharui pandanganpandangan keagamaan sebelumnya, yakni pandangan-pandangan Hamzah Fansuri dan

\footnotetext{
${ }^{2}$ Fazlur Rahman, Islam, University of Chicago Press, Chicago, 1979, hal. 137.

${ }^{3}$ Oman Fathurahman, Tanbîh al-Mâsŷ̂ Menyoal Wahdatul Wujud Kasus Abdurrauf Singkel di Aceh Abad 17, Mizan, Bandung, 1999, hal. 24, 36-37.
}

Syamsuddin as-Sumatrani, khususnya paham wujudiyah yang dipandang telah menyimpang dari batas-batas syariat Islam.

\section{B. NURUDDIN AL-RANIRÎ: PELOPOR SUFISME ORTODOKS}

Telah tercatat dalam sejarah, bahwa di Aceh pada masa pemerinta-han Sultan Iskandar Sani (1637-1641) telah terjadi kontroversi mengenai ajaran wujudiyah. Ajaran ini disebarluaskan oleh dua ulama besar, yakni Hamzah Fansuri dan Syamsuddîn al-Sumatranî. Hamzah adalah seorang ulama besar yang pernah melakukan perjalanan ke berbagai pusat pengetahuan Islam di Timur Tengah seperti Mekkah, Madinah, Yerusalem, Bagdad (di mana ia mengunjungi makam Syeikh 'Abdul Qâdir alJîlanî), dan Ayuthia yang ia sebut dengan nama Persianya, Shahru Nawi. Hamzah Fansuri adalah pengarang pertama dan penyair terbesar di kalangan para sufi di Nusantara. Ia mengungkapkan gagasan mistiknya dalam bentuk prosa dan syair yang penuh dengan berbagai perumpamaan. ${ }^{4}$

Hubungan antara Hamzah dan Syamsuddîn, meski kurang begitu jelas, adalah hubungan persahabatan yang mengisyaratkan adanya hubungan murid dan guru; Hamzah sebagai guru dan Syamsuddin adalah muridnya. Hamzah dan Syamsuddin memiliki pandangan dan pemikiran keagamaan yang sama. Keduanya mendukung ajaran mistik filosofis dari ajaran wahdat al-wujûd. Keduanya sangat dipengaruhi oleh Ibn Arabî dan al-Jillî dan mengikuti sistem doktrin wujûdiyah yang sangat rumit. $^{5}$ Pada umumnya, pandangan mereka bersifat pantheistik, suatu paham yang menjelaskan hubungan Tuhan dan manusia sebagai sesuatu yang tunggal dan tidak dapat dipisah-pisahkan.

Pandangan mistik filosofis yang berwatak pantheistik dari Ibnu Arabi ini sangat

\footnotetext{
${ }^{4}$ Martin van Bruinessen, Kitab Kuning Pesantren dan Tarekat Tradisi-Tradisi Islam di Indonesia Mizan, Bandung, 1995, hal. 190.

${ }^{5}$ Azyumardi Azra, Jaringan Ulama Timur Tengah dan Kepulauan Nusantara Abad XVII dan XVIII, Mizan, Bandung, 1999, hal. 166-168.
} 
menguasai pemikiran keagamaan di Aceh pada abad ke-16 hingga pertengahan abad ke-17 M, dan ajaran ini sangat berpengaruh karena dua pendukungnya: Hamzah dan Syamsuddîn adalah para sufi besar yang memegang peranan di Istana kerajaan. Bahkan pengaruh ajaran mistis pantheistik ini telah menjangkau masyarakar umum. ${ }^{6}$

Dalam berbagai karyanya, Hamzah Fansuri lebih menekankan imanensi Tuhan dan alam secara mutlak. Sebagai contoh, Hamzah menganalogikan hubungan antara Tuhan dan alam dengan pohon dan biji yang merupakan bibitnya. Walaupun tampaknya terdapat dua benda: pohon dan biji, tetapi pada hakekatnya satu. Hamzah juga menganalogi-kan hubungan antara Tuhan dan alam itu dengan matahari, cahaya, dan panasnya yang kelihatannya tiga tetapi pada dasarnya, satu juga. Karena pandangan Hamzah semacam itu, maka ia lebih toleran terhadap ungkapan-ungkapan ekstatik (syathahât) para sufi yang menunjukkan kesatuan antara Tuhan dan dirinya seperti dalam ucapan al-Hallâj, Ana al-Haq (Aku adalah Yang Maha Benar). Dalam keadaan biasa, menurut Hamzah, seseorang tidak diperkenankan menyatakan kesatuan dirinya dengan Tuhan, tetapi dalam keadaan fana, birahi dan mabuk, hal itu boleh dilakukan. ${ }^{7}$ Dalam perspektif akidah Islam, seseorang yang mengklaim dirinya sebagai Tuhan jelas dipandang telah melakukan perbuatan syirik. Namun Hamzah membedakan keadaan biasa dengan kondisi ekstasi yang dialami sang sufi dan dengan jelas ia memberikan toleransi terhadap syathahât yang muncul dari lisan kaum sufi.

Untuk melegitimasi gagasannya mengenai kesatuan wujud itu, Hamzah Fansuri dalam berbagai karyanya selalu memakai hadis: man 'arafa nafsahu faqad 'arafa rabbahu. Ia memahaminya kalimat man 'arafa nafsah bukan sebagai pengenalan terhadap jantung, paru-paru, kaki, tangan dan anggota badan lainnya, tetapi bahwa adanya makhluk dengan adanya Tuhan itu satu, seperti biji dan pohon; pohon terdapat dalam biji itu. Walaupun tidak kelihatan tetapi sebenarnya berada dalam biji itu. $^{8}$

Sebagai seorang ulama ortodoks yang lebih mementingkan pengamalan syariat, Nuruddîn al-Ranirî yang berada di Aceh dari tahun 1637 hingga $1644 \mathrm{itu}$, menganggap sesat ajaran wujûdiyah Hamzah dan Syamsuddîn. Syamsuddîn mengajarkan bahwa Allah itu ruh dan wujud kita dan bahwa kita adalah ruh dan wujud Tuhan. Berbeda dengan pendapat Hamzah dan Syamsuddin, dalam buku Asrâr al-Insân fi Ma'rifat al-Rûh wa al-Rahmân, ${ }^{9}$ Nuruddin dengan tegas menentang pendapat bahwa ruh itu qadîm. Menurutnya, ruh itu diciptakan Tuhan. Ia menentang keras perkataan "Ana al-Haq". Kalimat "man "arafah nafsah faqad 'arafa rabbah" dipahami sebagai berikut: Siapa yang mengenal dirinya sebagai makhluk, maka ia akan mengenal Tuhannya sebagai Pencipta. Siapa yang mengenal dirinya sebagai fanâ, maka ia akan mengenal Tuhannya sebagai baqa.$^{10}$

Perdebatan antara al-Ranirî dan pengikut wujûdiyah seringkali terjadi di hadapan Sultan dan Sultanah hingga memakan waktu yang cukup lama. Namun karena mereka gagal mengatasi masalah, maka al-Ranirî mengeluarkan fatwa bahwa doktrin wujûdiyah itu menyimpang dari batas akidah Islam. AlRanirî menganjurkan kepada para penganutnya untuk bertobat dan melepaskan diri dari paham

\footnotetext{
${ }^{6}$ Ahmad Daudy, Falsafah Mistik Syeikh Hamzah Fansuri dalam Sanggahan Syeikh Nuruddin Ar-Raniry, dalam al-Jami'ah edisi no. 27, 1982, hal. 30.

${ }^{7}$ Oman Fathurahman, Tanbîh al-Mâsŷ̀, hal. 53-54.

${ }^{8}$ Ibid., hal. 58-59.

${ }^{9}$ Karya ini mulai ditulis pada tahun 1640 atas perintah Sultan Iskandar Tsani dan diselesaikan sebelum tahun 1644 selama pemerintahan Sultanah Safiyatuddin. Beberapa karya Nuruddin al-Raniri lainnya dapat disebut misalnya: Sirât al-Mustaqîm, Durrat al-Farâ id bi Syarh
}

al-'Aqầid, Bustân al-Salâtîn, Tibyân fî̀ Ma'rifa alAdyân, Hujjat al-Siddîq li Daf' al-Zindîq, untuk lebih lengkapnya, lihat Syed Muhammad Naquib al-Attas, $A$ Commentary of Hujjat al-Siddîq of Nuruddin al-Raniri, Minister of Culture Malaysia, Kuala Lumpur,1986, hal. 24-28.

${ }^{10}$ Tudjimah, Asrâr al-Insân fî̀ Ma'rifa al-Rûh wa alRahmân, P.T. Penerbitan Universitas, Djakarta, t.t. hal. 5 . 
itu. Dan siapa saja yang tidak mengikuti fatwa itu diklaim kafir dan dapat dijatuhi hukuman mati. Karena sikap al-Ranirî itu didukung oleh penuh oleh Sultan Iskandar Sani, maka para pengikut Hamzah harus menanggung tindakan kekeras-an dari aparat kerajaan. Mereka dikejar-kejar dan dipaksa melepaskan keyakinannya terhadap doktrin wujûdiyah yang mereka anut. Bahkan atas anjuran Nuruddîn, buku-buku Hamzah Fansuri dikumpulkan dan dibakar di depan masjid raya Banda Aceh, Baiturrahman, karena karya-karya tersebut dianggap sebagai sumber penyimpangan akidah umat Islam. ${ }^{11}$ Tentu saja hal ini merupakan sikap berlebihan dari al-Ranirî dan para penentang paham wujûdiyah.

Bisa jadi sikap al-Ranirî yang tak kenal kompromi terhadap ajaran wujûdiyah itu disebabkan oleh pengalaman masa lalunya ketika hidup di lingkungan Hindu di India yang penuh dengan konflik sosial dan keagamaan antara kelompok muslim minoritas dan kelompok Hindu mayoritas yang membekas dalam dirinya. ${ }^{12}$ Meski demikian, tidak dapat diingkari bahwa kepribadian al-Ranirî yang bertindak tegas terhadap berbagai penyimpangan yang dilakukan oleh sebagian kalangan mistik mengingatkan kita kepada model tasawuf ortodoks yang selalu memagari ajaran-ajaran sufi dengan aturan-aturan syariat yang ketat, lebih-lebih ajaran yang terkait dengan transendensi Tuhan dan keesaan-Nya.

\section{C.SUMBANGAN ABDURRAUF AL- SINGKIL $\hat{\mathbf{I}}$}

Ulama selanjutnya yang memberikan sumbangan kepada gerakan pembaruan tasawuf adalah Abdurrauf al-Singkilî. Tidak kurang dari 19 tahun waktunya dihabiskan di Mekkah dan Madinah untuk belajar berbagai ilmu keislaman kepada para guru besar pada masanya. Guru yang paling berpengaruh terhadap pemikiran tasawuf Abdurrauf kelak

\footnotetext{
${ }^{11}$ Ibid., hal. 5; Azyumardi Azra, Jaringan Ulama, hal. 182; Oman Fathurahman, Tanbîh al-Mâsyî, hal. 36-37.

${ }^{12}$ Azyumardi Azra, Jaringan Ulama, hal. 182-183.

${ }^{13}$ Martin Van Bruinessen, Kitab Kuning Pesantren dan Tarekat Tradisi-Tradisi Islam di Indonesia, hal. 192-
}

adalah Ahmad al-Qusyasyî, guru spiritualnya di Madinah. Dari al-Qusyasŷ̂, Abdurrauf mengkaji ilmu tasawuf dan ilmu-ilmu yang terkait sampai ia memperoleh ijazah untuk menjadi khalifah dalam tarekat Syatariyah dan Qadiriyah. Setelah kembali ke Aceh pada tahun 1661, yakni setahun setelah gurunya, alQusyasyi, meninggal, ia menjadi pakar di bidang fiqih dan tasawuf sekaligus. ${ }^{13}$ Pemikiran keagamaannya mendapat sambutan hangat dari Sultanah Safiyatuddîn, yang pada saat itu masih memerintah kesultanan Aceh (1645-1675). Lalu Sultanah mengangkatnya sebagai Qadi Malik Adil, mufti yang bertanggung jawab atas administrasi berbagai persoalan keagamaan. ${ }^{14}$

Sebagai ulama yang menguasai ilmu-ilmu keislaman, Abdurrauf telah menghasilkan berbagai karya yang meliputi bidang fikih, tasawuf, tafsir, dan hadis. Di bidang fikih, dapat disebut, misalnya, Mir`ât al-Tullâb fî̀ Tahshîl Ma'rifah al-Ahkâm al-Syar'iyyah lî alMâlik al-Wahhâb, Bayân al-Arkân, Bidâyah al-Bâligah, Majmû' al-Masâ'il, Fâtihah Syeikh Abdurrauf, Tanbîh al-Âmil fî Tahqîq Kalâm alNawâfil, dan lain lainnya. Sedangkan karyakarya di bidang tasawuf antara lain: Tanbîh alMâsŷ̀ al-Mansûb ilâ Tarîq al-Qusyasyiy, 'Umdatul Muhtâjîn, Sullâm al-Mustafídîn, Kifâyat al-Muhtâjîn, Bayân Tajallî, Daqầiq al-Hurûf, dan sebagainya. ${ }^{15}$

Sama dengan al-Ranirî, al-Singkilî dalam ajaran-ajaran mistiknya selalu mempertahankan transendensi Tuhan. Ia menolak paham wujûdiyah yang menekankan imanensi Tuhan dalam makhluk-Nya. Menurutnya, sebelum Tuhan menciptakan alam raya, Tuhan selalu memikirkan diri-Nya sendiri yang menyebabkan terciptanya Nur Muhammad. Dari Nur Muhammad itu, Tuhan menciptakan potensi alam raya yang menjadi sumber dari ciptaan dalam bentuk konkritnya. Walaupun alam dalam bentuk konkritnya ini

193; lihat juga Bambang Widiatmoko, "WahdatulWujud Analisis Kritis Abdurrauf Singkel," dalam Basis edisi 48, 1999, hal. 36.

${ }^{14}$ Oman Fathurahman, Tanbîh al-Mâsŷ̂, hal. 27-28.

${ }^{15}$ Ibid., hal. 28-30. 
merupakan hasil emanasi Tuhan, namun alam itu berbeda dengan Tuhan sendiri; keduanya ibarat tangan dan bayangannya. Meskipun tangan tidak dapat dipisahkan dari bayangannya, tetapi keduanya tidaklah sama. Jadi, Tuhan menurut al-Singkilî tetap transenden, yakni mengatasi ciptaan-Nya.

Al-Singkilî memang mengakui pentingnya intuisi dalam jalan mistik, tetapi ia sekaligus mengakui keterbatasan kata-kata untuk mengungkap-kan dan memahami hakekat Tuhan. Ia banyak dipengaruhi oleh konsepkonsep al-Kurani mengenai Tawhîd alUlûhiyyah (keesaan Tuhan), Tawhîd al-Af'âl (keesaan perbuatan Tuhan), Tawhî̀d as-Shifat (keesaan sifat-sifat Tuhan), Tawhî̀ al-Wujûd (keesaan wujud Tuhan), Tawhî̀ al-Dzât (keesaan esensi Tuhan) serta Tawhî̀ al-Haqîqî (keesaan Realitas Mutlak). ${ }^{16}$ Ajaran-ajaran alSingkilî ini jelas menunjukkan ciri-ciri ortodoksi yang ingin membuktikan bahwa tasawuf harus seiring dengan syariat. Karena hanya dengan kepatuhan pada syariat, seorang sâlik dapat mencapai ahwâl, pengalaman mistik.

Sikap al-Singkilî memang sangat berbeda dengan sikap al-Ranirî. Ia adalah pembaharu evolusioner, bukan pembaharu radikal. Seperti gurunya, al-Kurani, ia lebih suka mendamaikan pandangan-pandangan yang saling bertentangan daripada menolak salah satu dari keduanya secara tegas. Meskipun ia tidak setuju dengan paham wujûdiyah, tetapi ketidaksetujuannya itu hanya diungkapkan secara implisit.

Selain itu, ia juga menunjukkan keberatannya pada cara-cara radikal yang ditempuh al-Ranirî. Jika al-Ranirî tampak tidak mengenal kompromi atas berbagai penyimpangan dari ajaran Hamzah dan Syamsuddîn, maka al-Singkilî lebih berhatihati. Ia tidak mau terjebak ke dalam sikap saling mengkafirkan sesama muslim. Bahkan ia mengingatkan kaum muslim akan bahaya mengkafirkan orang lain dengan mengutip

\footnotetext{
${ }^{16}$ Azyumardi Azra, Jaringan Ulama, hal. 206-208.

${ }^{17}$ Ibid., hal. 208. Oman Fathurahman, Tanbih alMasyi, hal. 52 dan 64.
}

hadis nabi, "Janganlah menuduh orang lain melakukan kekafiran, sebab tuduhan itu akan berbalik jika memang tidak benar. ${ }^{17}$ Dengan demikian, bisa dikatakan, bahwa ia lebih bijak dan toleran dalam menghadapi konflik antara dua kelompok tasawuf tersebut.

Abdurrauf al-Singkilî sangat memperhatikan aspek syariat. Dalam Tanbîh al-Mâsŷ̀, aspek syariat pertama yang diungkapkan al-Singkilî adalah perintah Nabi untuk membaca shalawat kepadanya. Seorang sâlik, menurutnya, seharusnya membaca shalawat sebanyak tiga ratus kali dalam sehari. Aspek moral, akhlak atau etika yang dalam pelaksanaannya harus meneladani Nabi Muhammad secara utuh diungkapkan pula. Aspek syariat lain yang menjadi perhatian alSingkilî adalah pembacaan serangkaian wirid, ayat, shalawat, dan doa serta amalan shalat sunnah yang harus dilaksanakan dalam jumlah tertentu dan pada saat tertentu pula. Amalanamalan tersebut, menurutnya, harus senantiasa dilandasi oleh Quran dan hadis. ${ }^{18}$ Dengan menjalankan syariat dan zikir yang kontinyu ini, tujuan seorang penempuh jalan sufi dapat dicapai.

\section{NEO-SUFISME SYEIKH YUSUF AL- MAKASARÎ}

Tokoh sufi selanjutnya yang ikut berperan dalam mengembangkan tradisi neosufisme adalah Syeikh Yusuf al-Makasarî yang lahir di Kerajaan Gowa pada 1626 M. Ia adalah seorang ulama syariat, sufi, khalifah tarekat, dan seorang musuh besar bagi kompeni Belanda. Ia dianggap sebagai "duri dalam daging" oleh pemerintah kompeni. Karena itu, ia diasingkan ke Ceylon, Sri langka, kemudian dipindahkan ke Afrika Selatan dan wafat di Cape Town, Afrika Selatan pada tahun 1699 M. Ia menjadi peletak dasar bagi kehadiran komunitas muslim di Afrika Selatan dan Ceylon. Di Afrika Selatan, ia bahkan dianggap sebagai bapak bagi komunitas-komunitas di Afrika Selatan yang berjuang mewujudkan

\footnotetext{
${ }^{18}$ Oman Fathurahman, Tanbîh al-Mâsŷ̂, hal. 76-83.
} 
persatuan dan kesatuan untuk menentang penindasan dan perbedaan kulit. ${ }^{19}$ Jika kita membaca perjalanan hidup Syeikh Yusuf, maka akan terlihat bahwa kesalehan mistiknya ternyata tidak menghalanginya dari militansi politik. ${ }^{20}$

Tidak berbeda dengan al-Ranirî dan alSingkilî, dalam mengembangkan doktrin sufisme, al-Makasarî seringkali mengutip berbagai pendapat para sufi ortodoks seperti alGhazâlî, Junayd al-Bagdâdî, Ibn 'Arabî, al-Jillî, Ibnu 'Atâ'illâh dan tokoh-tokoh lainnya. Ajaran pokok al-Makasarî tentang tasawuf adalah pemurnian kepercayaan (aqidah) pada Keesaan Tuhan sebagai upaya untuk menekankan transendensi Tuhan atas makhlukNya. Al-Makasarî menegaskan bahwa keesaan Tuhan itu tak terbatas dan mutlak. Meskipun ia berpegang teguh pada transendensi Tuhan, tetapi al-Makasarî percaya bahwa Tuhan itu mencakup segalanya (al-ahathah) dan ada di mana-mana (al-ma'iyyah) atas ciptaan-Nya. Ia sangat berhati-hati agar tidak terjatuh dalam paham pantheisme.

Oleh sebab itu, al-Makasarî mengatakan, meskipun Tuhan menam-pakkan dirinya dalam ciptaan-Nya, hal itu tidak berarti bahwa ciptaan-Nya itu adalah Tuhan sendiri. Wujud semua ciptaan-Nya hanyalah wujud majazi dan bukan wujud hakiki. Dengan demikian, ciptaan Tuhan hanya bayangan-Nya, dan bukan hakekat diri-Nya. Memang bisa saja terjadi tanazzul, Tuhan turun, sementara manusia naik atau taraqqî sehingga keduanya semakin dekat. Tetapi kedekataannya tidak sampai mengambil bentuk penyatuan eksistensi. Manusia tetap manusia dan Tuhan tetap Tuhan. Dengan demikian, konsep wahdatul wujûd dan hulûl jelas tertolak dengan penjelasan ini. ${ }^{21}$

Tasawuf yang dikembangkan al-Makasarî jelas menunjukkan ciri-ciri sufisme ortodoks.

\footnotetext{
${ }^{19}$ Abu Hamid, Syeikh Yusuf: Seorang Ulama, Sufi dan Pejuang, Yayasan Obor Indonesia, Jakarta, 1994, hal. xxiii. Syeikh Yusuf juga meninggalkan banyak karya seperti: Al-Barakat al-Saylaniyyah, Bidâyat al-Mubtadî, Daf' al-Balâ', Fath Kaifiyyât al-Zikr, Al-Fawầih alYusufiyah fî Bayân Tahqî̀ al-Sûfiyyah, Hablul Warîd li Sa'âdat al-Murîd, Matâlib al-Sâlikîn, Qurratul 'Ain, Safînatun Najâh, Sirr al-Asrâr, Zubdat al-Asrâr, dan lain
}

Ia menyebut tasawuf dengan "tarekat alMuhammadiyah" atau "tarekat al-Ahmadiyah" sebagai jalan yang benar. Dalam berbagai tulisannya, ia mengatakan bahwa jalan sufi hanya dapat dicapai dengan kesetiaan penuh pada hukum Islam, baik secara lahiriah maupun batiniah. Ia menegaskan, orang yang hanya berpegang pada syariat lebih baik daripada orang yang mengamalkan tasawuf tanpa memperhatikan aturan syariat. Menurutnya, orang-orang yang percaya bahwa mereka dapat mendekat dan semakin dekat dengan Tuhan tanpa melakukan ibadah seperti shalat dan puasa dikatakannya sebagai zindîq dan mulhid.

Berulangkali ia mengutip pernyataan para sufi yang menyatakan bahwa orang-orang yang hanya mementingkan aspek syariat tanpa hakekat adalah fasik dan orang-orang yang menempuh jalan sufi tanpa mematuhi syariat adalah zindîq. Yang terbaik, menurutnya, adalah menyelaraskan keduanya. Al-Makasarî pernah mengatakan, "Hendaknya diketahui, kawan-kawanku, ketaatan eksoteris tanpa ketaatan esoteris adalah seperti tubuh tanpa jiwa, sedangkan keasyikan esoteris tanpa ketaatan eksoteris adalah bagaikan jiwa tanpa tubuh." Padahal, katanya, Nabi diutus oleh Tuhan untuk membawa syariat dan hakekat sekaligus. Karena itulah, maka setiap orang harus mengamalkan seluruh ajaran syariat sebelum memasuki dunia tasawuf. ${ }^{22}$ Dari penjelasan ini, tampak-lah bahwa al-Makasarî juga ikut andil dalam mengembangkan pemikiran tasawuf ortodoks yang sudah digagas lebih dulu oleh para sufi seperti alRanirî dan al-Singkilî.

Ia selanjutnya mengemukakan berbagai cara mendekatkan diri kepada Tuhan. Pertama, cara akhyâr (orang-orang terbaik), yakni dengan mengerjakan banyak shalat, membaca al-

sebagainya, lihat karya-karya Sheikh Yusuf al-Makasari sekaligus dengan ringkasannya dalam Nabilah Lubis, Syekh Yusuf al-Taj al-Makasari Menyingkap Intisari Segala Rahasia, Mizan, Bandung, 1996, hal. 29-50.

${ }^{20}$ Martin Van Bruinessen, Tarekat Naqsyabandiyah di Indonesia, Mizan, Bandung, 1998, hal. 34-36.

${ }^{21}$ Azyumardi Azra, Jaringan Ulama, hal. 232-233.

${ }^{22}$ Ibid., hal. 236-237. 
Quran dan hadis, berjuang di jalan Allah dan ketaatan eksoteris lainnya. Kedua, adalah mujâhidat al-syaqa', yakni dengan jalan latihan keras untuk melepaskan diri dari kebiasaan buruk serta menyucikan pikiran dan jiwa. Ketiga adalah cara ahli zikir, orang-orang yang mencintai Tuhan secara lahir maupun batin. ${ }^{\mathbf{2 3}}$

Akan tetapi, al-Makasarî mengingatkan kepada para penempuh jalan sufi untuk tidak berjalan sendiri dalam mencari kebenaran tanpa bimbingan dari seorang guru yang disebut syeikh karena hal itu dapat menyesatkan dirinya. Hanya lewat gurulah, seorang sâlik akan mampu mendekati Tuhan. Lebih jauh dikatakan bahwa syeikh tarekat bagaikan khalifah Tuhan yang memiliki sejumlah sifat Tuhan. Oleh sebab itu, seorang murid harus mengetahui bahwa ketika ia berbaiat kepada gurunya, berarti ia berbaiat kepada Tuhannya. ${ }^{24}$

Demikianlah, ketiga tokoh sufi tersebut di atas menunjukkan titik-titik persamaan, yakni bahwa mereka sama-sama memberikan sumbangan kepada pengembangan model tasawuf ortodoks dengan cara menekankan transendesi Tuhan atas makhluknya dan dengan cara mengikat pengalaman batin dengan aturan-aturan syariat. Sampai sejauh ini, upaya mereka dapat dikatakan berhasil, walalupun tindakan radikal al-Ranirî juga patut disesalkan karena dengan begitu kita telah banyak kehilangan karya-karya tasawuf heterodoks. Apalagi hal itu disertai dengan tindakan takfîr, pengkafiran dan pembunuhan terhadap lawan mereka.

\section{E. KESIMPULAN}

Dari kajian tersebut dapat disimpulkan bahwa sumbangan Nuruddin al-Ranirî, Abdurrauf al-Singkilî, dan Syeikh Yûsuf alMakasarî dalam pengembangan model sufisme ortodoks di Nusantara tidak diragukan lagi. Ajaran-ajaran tasawuf para sufi Sumatra ini sebagaimana terlihat dalam uraian-uraian mereka dengan jelas menunjukkan ciri-ciri tasawuf amali yang selalu mengikat pengalaman mistik dengan aturan syariat.

\footnotetext{
${ }^{23}$ Ibid., hal. 237-238.
}

Tokoh-tokoh sufi tersebut tidak ingin jatuh dalam pandangan pantheistik, suatu paham penyatuan antara Tuhan dan manusia, sebagaimana diajarkan oleh para penganut ajaran wujûdiyah: Hamzah Fansuri dan Syamsuddin as-Sumatrani.

Oleh sebab itu, tema sentral pembahasan mereka berkisar seputar transendensi Tuhan atas ciptaan-Nya di samping ajaran mengenai kepatuhan kepada aturan syariat. Mereka, baik secara tegas seperti yang dilakukan al-Ranirî maupun secara implisit seperti al-Singkilî dan al-Makasarî, mempertahankan transendensi Tuhan untuk menolak pandangan wujûdiyah dari Hamzah dan Syamsuddîn. Secara umum, mereka berpendapat bahwa meskipun Tuhan bisa saja turun (tanazzul) sementara manusia naik (taraqqî) sehingga mereka menjadi dekat dan semakin dekat, tetapi keduanya tetap berbeda dan tidak akan bersatu. Tuhan yang bertanazzul tetap sebagai Tuhan dan manusia yang bertaraqqî tetap saja sebagai manusia.[]

\section{F. DAFTAR PUSTAKA}

Hamid, Abu, Syekh Yusuf: Seorang Ulama, Sufi dan Pejuang, Yayasan Obor Indonesia, Jakarta, 1994.

Daudy, Ahmad, Falsafah Mistik Syeikh Hamzah Fansuri dalam Sanggahan Syeikh Nuruddin ar-Raniry, dalam Al-Jami'ah Edisi 27, 1982.

Attas, Syed Muhammad Naquib al-. A Commentary on the Hujjat al-Siddîq of Nûr al-Dîn al-Rânîrî, Ministry of Culture, Malaysia, 1986.

Azra, Azyumardi. Jaringan Ulama Timur Tengah dan Kepulauan Nusantara Abad XVII dan XVIII, Mizan, Bandung, 1999.

Bruinessen, Martin Van, Tarekat Naqsabandiyah di Indonesia, Mizan, Bandung, 1998. , Kitab Kuning Pesantren dan Tarekat Tradisi-Tradisi Islam di Indonesia, Mizan, Bandung, 1995.

Rahman, Fazlur, Islam, University of Chicago

\footnotetext{
${ }^{24}$ Nabila Lubis, Syeikh Yusuf al-Taj al-Makasari Menyingkap Intisari Segala Rahasia, hal. 57-58.
} 
Press, Chicago, 1979.

Lubis, Nabilah, Menyingkap Intisari Segala Rahasia Karangan Syekh Yusuf al-Taj alMakasari, Mizan, Bandung, 1996.

Fathurahman, Oman, Tanbîh al-Mâsŷ̀ Menyoal Wahdatul Wujud Kasus Abdurrauf Singkel di Aceh Abad 17, Mizan, Bandung, 1999.

Tudjimah, Asrâr al-Insân fi Ma'rifa al-Rûh wa 'l-Rahmân, P.T. Penerbitan Universitas, Jakarta, t.t. 